\title{
Short and Long Term Structural Response to Irregular Seas of a 112 m Length Tanker
}

\author{
José R. Marín L., Ph.D. ${ }^{1}$, and Lissette P. Salazar L., B.Sc. ${ }^{2}$ \\ ${ }^{1}$ Escuela Superior Politécnica del Litoral, Ecuador, jrmarin@espol.edu.ec \\ ${ }^{2}$ SLEM S.A., Ecuador, lsalazar@slemsa.com.ec
}

\begin{abstract}
In this work, structural response (Vertical Shear Force, SFZ, and Lateral Bending Moment, BMY) to irregular seas for a 7440 DWT and 112-m Ibp tanker is calculated for three loading conditions, traveling at constant speed. SCORES computer program was used to linearly calculate the response on regular waves, obtaining the Response Amplitude Operators (RAO) of the Internal forces for different wave lengths and angles of incidence. To calculate Internal Forces at irregular waves, Short and Long Term load prediction methods were implemented. In both cases Spectra of the internal forces were calculated using Bretschneider formulation to represent the surfave elevation. For the first approach, navigation was considered in stationary conditions in three sea states: 5, 6 and 7 of the Beaufort scale, and with probabilities of exceedance of 10-7, 10-8 and 10-9. For the Long term approach, it was considered 20 years of navigation for a constant route between South America and Western Europe, and calculations were performed with a probability of exceedence of 108 and 10-9. These calculations were performed using Weibull distribution, including a simple process to estimate its parameters. Finally, these results from probabilistic Short and Long Term approaches were compared with formulas from DNV classification society, and with results from classic quasistatic approach, obtaining acceptable differences.
\end{abstract}

Keywords - Structural Random response, Small tanker, irregular seas.

Digital Object Identifier (DOI): http://dx.doi.org/10.18687/LACCEI2015.1.1.238

ISBN: 13 978-0-9822896-8-6

ISSN: 2414-6668

13 ${ }^{\text {th }}$ LACCEI Annual International Conference: “Engineering Education Facing the Grand Challenges, What Are We Doing?” July 29-31, 2015, Santo Domingo, Dominican Republic DOI: http://dx.doi.org/10.18687/LACCEI2015.1.1.238 


\title{
Short and long term structural response to irregular seas of a 112 m length tanker
}

\author{
José R. Marín L., Ph.D. ${ }^{1}$, and Lissette P. Salazar L., B.Sc. ${ }^{2}$, \\ ${ }^{1}$ Escuela Superior Politécnica del Litoral, Ecuador, jrmarin@espol.edu.ec \\ ${ }^{2}$ SLEM S.A., Ecuador, 1salazar@slemsa.com.ec
}

\begin{abstract}
In this work, structural response (Vertical Shear Force, SFZ, and Lateral Bending Moment, BMY) to irregular seas for a 7440 DWT and 112-m lbp tanker is calculated for three loading conditions, traveling at constant speed. SCORES computer program was used to linearly calculate the response on regular waves, obtaining the Response Amplitude Operators (RAO) of the Internal forces for different wave lengths and angles of incidence. To calculate Internal Forces at irregular waves, Short and Long Term load prediction methods were implemented. In both cases Spectra of the internal forces were calculated using Bretschneider formulation to represent the surfave elevation. For the first approach, navigation was considered in stationary conditions in three sea states: 5, 6 and 7 of the Beaufort scale, and with probabilities of exceedance of $10^{-7}, 10^{-8}$ and $10^{-9}$. For the Long term approach, it was considered 20 years of navigation for a constant route between South America and Western Europe, and calculations were performed with a probability of exceedence of $10^{-}$ ${ }^{8}$ and $10^{-9}$. These calculations were performed using Weibull distribution, including a simple process to estimate its parameters. Finally, these results from probabilistic Short and Long Term approaches were compared with formulas from DNV classification society, and with results from classic quasistatic approach, obtaining acceptable differences.
\end{abstract}

Keywords-Structural Random response, Small tanker, irregular seas.

\section{INTRODUCTION}

The length of a ship is usually much larger than the width (Breadth) and height (Depth), so in a simplified model, it is considered a beam with varying section, a hull beam. For her structural design, in the vertical plane maximum values of Shear Force, SFZ, and Bending moment, BMY, are selected, which be endured during her entire life. Then, structure scantlings may be selected so that it has enough sectional area and sectional modulus, resulting in shear and normal stresses which do not exceed permissible levels.

Since a ship operates in irregular waves, with random nature, her response will have that characteristic, and the estimation of the internal forces for design must be developed applying statistics, [1]. Ship classification societies provide simple formulas to estimate SFZ and BMY when ship operates in waves, for example [2]. Also it is possible to estimate those internal forces assuming a quasistatic equilibrium in a equivalent waves, in situations known as Sagging (Wave trough at Midships) and Hogging (Wave crest at midships), [1]. However the application of closed formulas do not allow to visualize the physical details of the phenomena, which restricts the confidence in its use, and therefore, its usefulness.
In the so called Short term approach, a ship structure is subject to an extreme sea state, to determine its response spectrum, which in the present case, are the Shear force and Bending moment to be applied for her design. Then take some characteristics from that function to generate the Probabiliy density function, pdf, and finally taking adequate values of probability of exceedance, determine $S F Z$ and $B M Y$ for the design. In the Long term approach, frequency of sea states in the vessel's route must be combined, to estimate the number of peaks to encounter in her entire life; then using the response to each of sea state, produce a pdf which allows to calculate design values of internal forces, whose probability of exceedence correspond to the inverse of number of maximum to be encountered, [2] and [3].

In this work it is intended to estimate the SFZ and BMY developed in a 7440 DWT tanker ship subject to irregular seas using short and term approaches, and compare them with the results of a classification society formulation and quasistatic method, [4]. Ship's life is 20 years, and hours of work per year were taken from real situations. With this work, those dynamic estimations will be developed in a more realistic way, and this will allow gain confidence in using the formulations from ship classification societies.

\section{RESPONSE IN REGULAR WAVES}

\section{A. Description of the ship}

The ship analyzed in this work has the proportions commonly found in ecuadorian waters for coastal water services, [5]. In the following figure and table there are shown her main dimensions and general distribution:

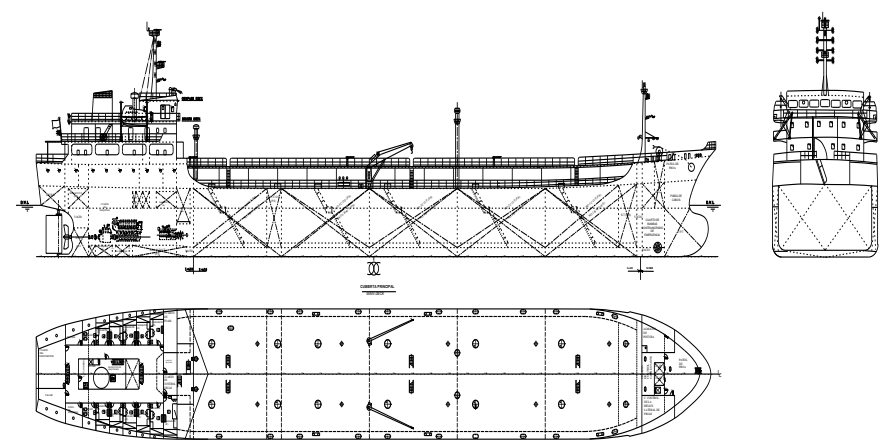

Fig. 1 General distribution plan. 
TABLE I

MAIN DIMENSIONS

\begin{tabular}{|l|c|c|}
\hline Length between perpendiculars & 112.00 & $\mathrm{~m}$ \\
\hline Breadth & 17.20 & $\mathrm{~m}$ \\
\hline Depth & 8.90 & $\mathrm{~m}$ \\
\hline Draft design & 6.70 & $\mathrm{~m}$ \\
\hline Block coefficient & 0.772 & \\
\hline Midship Section coefficient & 0.979 & \\
\hline Velocity & 12 & knots \\
\hline
\end{tabular}

Three load conditions were selected for the analysis, which cover the range of extreme operational weights. See table II.

TABLE II

LOADING CONDITIONS (LIGHTWEIGHT: 2850 TONS)

\begin{tabular}{|l|l|c|c|c|}
\hline$\#$ & Description & $\begin{array}{l}\text { Displac } \\
\text {., tons }\end{array}$ & $\begin{array}{l}\text { Mean } \\
\text { Draft, } \mathrm{m}\end{array}$ & $\begin{array}{l}\text { Trim, m, } \\
+\mathrm{Aft}\end{array}$ \\
\hline 1 & Ballast with consumables at 10\% & 5525 & 3.84 & 2.17 \\
\hline 2 & $78 \%$ Load \& Consumables at 10\% & 8348 & 5.58 & 2.58 \\
\hline 3 & Load \& Consumables at 100\% & 10286 & 6.72 & 1.34 \\
\hline
\end{tabular}

Following there are shown graphically weight distributions for each of the ship loading conditions.

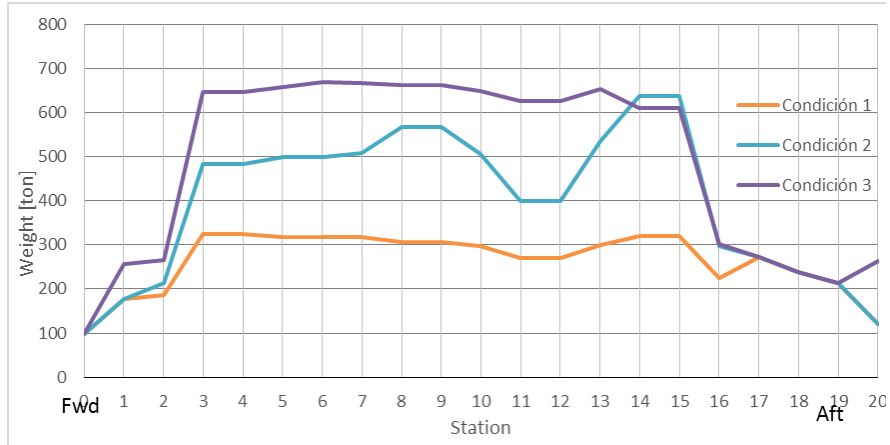

Fig. 2 Weight distributions for loading conditions.

With these weight distributions, the vessel may be equilibrated in still water, and then internal force and moment may be calculated for different sections along its length. Following those results are shown, for the three loading conditions.

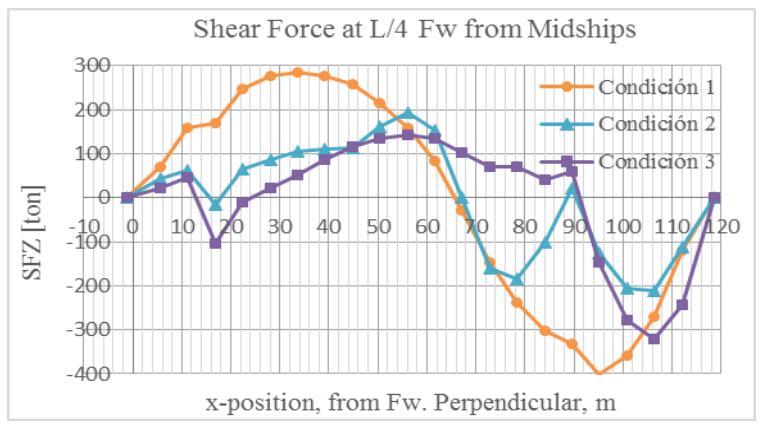

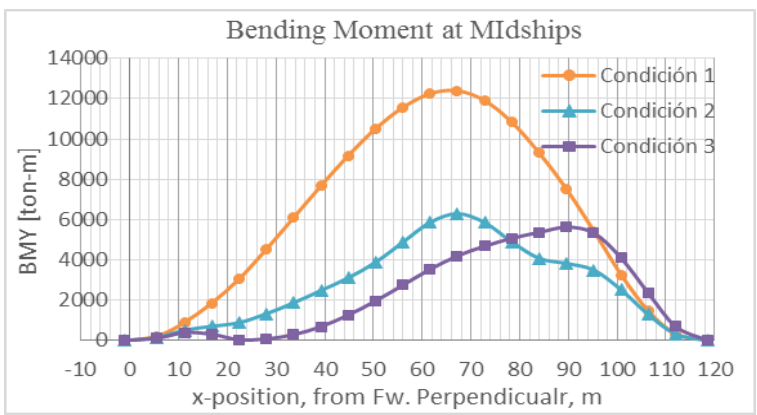

Fig. 3 Still water Internal forces.

B. Shear Force and Bending Moment in regular waves

Considering the ship as a rigid body, and assuming a linear behavior, the response to regular waves was calculated using computer program SCORES, [6], which uses Strip theory. For a unitary wave, the amplitudes of Shear Force at and Bending moment, correspond to Response Amplitude Operators, $R A O \mathrm{~s}$. Incident wave length was varied between $0.2 \mathrm{~L}$ and $3 \mathrm{~L}$, and angle of incidence from $90^{\circ}$ (beam seas) until $180^{\circ}$ (from the bow).
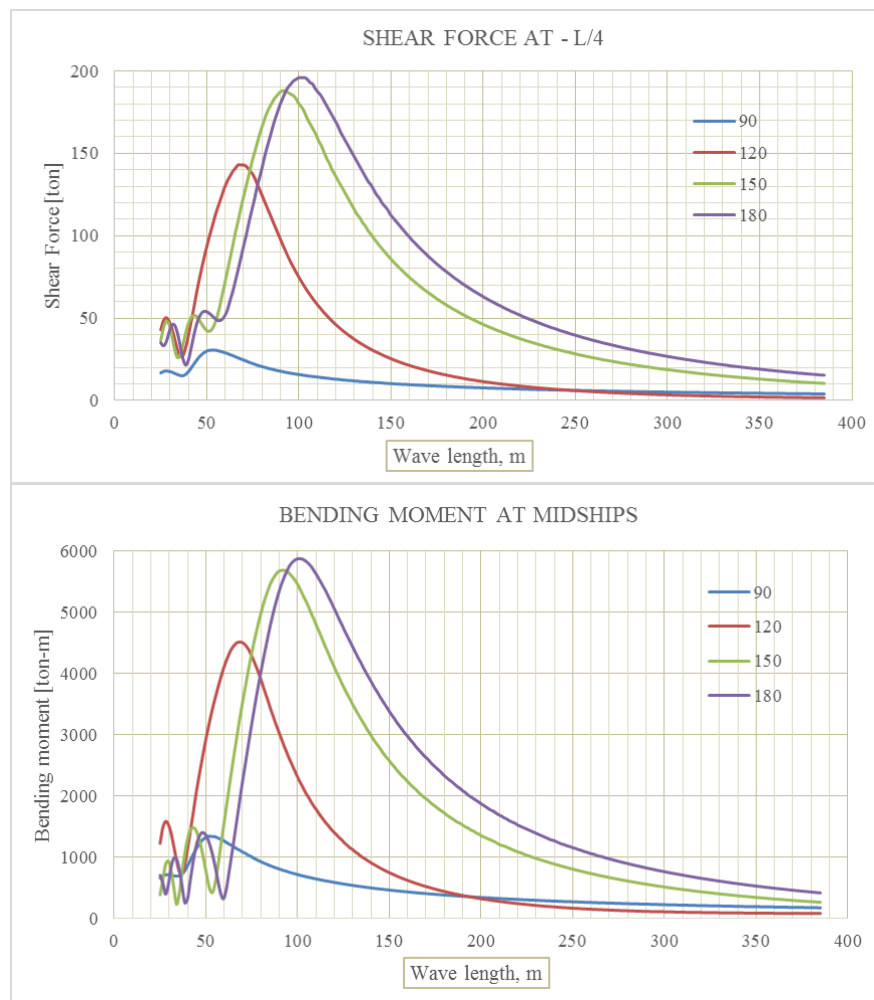

Fig. 4 SFZ and BMY for load condition 1

Maximum Shear force appears $L / 4$ forward from midships, and maximum Bending moment at midships, in both cases when the ship receives waves from the bow $\left(\beta=180^{\circ}\right)$,

$1^{\text {th }}$ LACCEI Annual International Conference: "Engineering Education Facing the Grand Challenges, What Are We Doing?" July 29-31, 2015, Santo Domingo, Dominican Republic 
and in condition 1 , with lower weight. For all calculations ship speed was taken 12 knots.

\section{SHORT TERM APPROACH}

\section{A. Sea states}

To represent the sea elevation with its probabilistic behavior, an Spectral density function is commonly used, which describes energy distribution as a function of frequency of components. In this work, Bretschnider formulation is used for Sea spectra, which requires wave significant height and modal period (frequency at max. value of the spectra), [7]. Calculations were performed for sea states 5, 6 and 7 according to Beaufort scale, which are above level 4, considered typically as standard. This calculation also assumes that the process is Stationary, which is usually acceptable for a "short" period of time between 30 and 120 minutes.

In this work, Bretschneider formulation (SI units) for the Spectral density function of sea waves is used, [7]:

$$
\begin{array}{r}
S(\omega)=\frac{A}{\omega^{5}} \exp \left(-\frac{B}{\omega^{4}}\right) \\
A=\frac{5}{16} \omega_{m}^{4} H_{1 / 3}^{2} \\
B=\frac{5}{4} \omega_{m}^{4}
\end{array}
$$

where:

$H_{1 / 3}$ : Significant wave height, and,

$\omega_{m}$ : modal frequency (at maximum energy).

Following there are shown parameters for each of the mentioned sea states:

TABLE III

SEA STATE PARAMETERS

\begin{tabular}{|c|c|c|c|c|c|}
\hline \multirow{2}{*}{$\begin{array}{c}\text { Beaufort } \\
\text { Scale }\end{array}$} & $\begin{array}{c}\text { Aver. Wave } \\
\text { Height }\end{array}$ & $\begin{array}{c}\text { Sig. Wave } \\
\text { Height }\end{array}$ & $\begin{array}{c}\text { Aver. Wave } \\
\text { Length }\end{array}$ & $\begin{array}{c}\text { Max. Ener. } \\
\text { Period, } \mathrm{T}_{\mathrm{m}}\end{array}$ & $\begin{array}{c}\text { Average } \\
\text { Period }\end{array}$ \\
\cline { 2 - 6 } & \multicolumn{5}{|c|}{$[\mathrm{m}]$} \\
\hline $\mathbf{5}$ & 1.40 & 2.22 & 33.84 & 7.5 & 5.4 \\
\hline $\mathbf{6}$ & 2.35 & 3.75 & 57.31 & 9.8 & 7.0 \\
\hline 7 & 3.54 & 5.67 & 86.89 & 12.1 & 8.6 \\
\hline
\end{tabular}

To consider the spread of incident waves, the following squared cosine model is used:

$$
S_{X}(\omega, \beta)=S(\omega) \frac{2}{\pi} \cos ^{2}(\beta)
$$

where $\beta$ is the incidence angle $\left(90^{\circ}\right.$ : waves from side, $180^{\circ}$, from bow).

\section{B. Response Spectra}

Assuming a liner behavior of the ship with respect to esciting waves, combination of its response to regular waves, $R A O$, and spectrum of the sea state, $S_{X}$, results in Response spectrum, $S_{Y}$, using the following equation, [3]:

$$
\begin{gathered}
S_{Y}(\omega, \beta)=R A O(\omega)^{2} S_{X}(\omega, \beta), \text { or, } \\
S_{Y}(\omega, \beta)=R A O(\omega)^{2} \frac{A}{\omega^{5}} \exp \left(-\frac{B}{\omega^{4}}\right) \frac{2}{\pi} \cos ^{2}(\beta) .
\end{gathered}
$$

The linearity assumption also implies, [3], that if the exciting wave is random stationary process with zero average Normal distribution, the response will have the same characteristics.

With respect to the band of the random phenomena, if the input process is narrow, not necessarily the output will have that characteristic. So it is necessary to calculate the band width, $\varepsilon$, to determine if the responses ( $S F Z$ and $B M Y$ ) are narrow banded, which allow to include some simplifications. For this, the following equation may be used, [3]:

$$
\varepsilon=\sqrt{1-\frac{m_{2}^{2}}{m_{0} m_{4}}}, 0 \leq \varepsilon \leq 1,
$$

\begin{tabular}{|c|c|c|c|c|c|c|}
\hline \multirow{3}{*}{$\begin{array}{l}\text { Sea } \\
\text { state }\end{array}$} & \multicolumn{3}{|c|}{ Shear Force at L/4 } & \multicolumn{3}{|c|}{ Bending Moment at midships } \\
\hline & $\mathbf{m}_{0}$ & $\mathbf{m}_{2}$ & $\mathbf{m}_{4}$ & $\mathbf{m}_{0}$ & $\mathbf{m}_{2}$ & $\mathbf{m}_{4}$ \\
\hline & ton $^{2}$ & $\operatorname{ton}^{2} / \mathrm{s}^{2}$ & $\operatorname{ton}^{2} / \mathrm{s}^{4}$ & $(\text { ton } \mathrm{m})^{2}$ & $(\text { ton } \mathrm{m})^{2} / \mathrm{s}^{2}$ & $(\text { ton } \mathrm{m})^{2} / \mathrm{s}^{4}$ \\
\hline & \multicolumn{6}{|c|}{ Load condition 1} \\
\hline 5 & 3896 & 4902 & 7095 & 3490262 & 4312817 & 5977886 \\
\hline 6 & 5834 & 6609 & 8830 & 5225845 & 5849959 & 7541216 \\
\hline \multirow[t]{2}{*}{7} & 6826 & 7313 & 9433 & 6094827 & 6478151 & 8086241 \\
\hline & \multicolumn{6}{|c|}{ Load condition 2} \\
\hline 5 & 3579 & 4160 & 5616 & 3265323 & 3802579 & 5120013 \\
\hline 6 & 5982 & 6031 & 7321 & 5515835 & 5532119 & 6683087 \\
\hline \multirow[t]{2}{*}{7} & 7466 & 7179 & 7991 & 6931377 & 6381060 & 7304714 \\
\hline & \multicolumn{6}{|c|}{ Load condition 3} \\
\hline 5 & 3363 & 3655 & 4679 & 3239829 & 3545400 & 4599671 \\
\hline 6 & 6137 & 5668 & 6372 & 5995550 & 5515545 & 6239230 \\
\hline 7 & 7962 & 6717 & 7094 & 7844217 & 6562495 & 6947807 \\
\hline
\end{tabular}

where $m_{n}$ is the nth moment of the Response spectrum density:

$$
m_{n}=2 \int_{\pi / 2}^{\pi} d \beta \int_{0}^{\infty} d \omega \omega^{n} S_{Y}(\omega, \beta)
$$

In the following table results for moments are presented:

TABLE IV

CHARACTERISTICS OF RESPONSE SPECTRA 
In the following figures, bandwidth parameter $\varepsilon$ is presented for both parameters, as a function of sea state. As is mentioned in [3], if this number is less than 0.60, the phenomena may be considered as narrow banded. This means that the energy is concentrated in a relatively narrow band of frequencies, and some simplifications of probability of exceedence maybe performed. It looks this is the case for the present analysis.

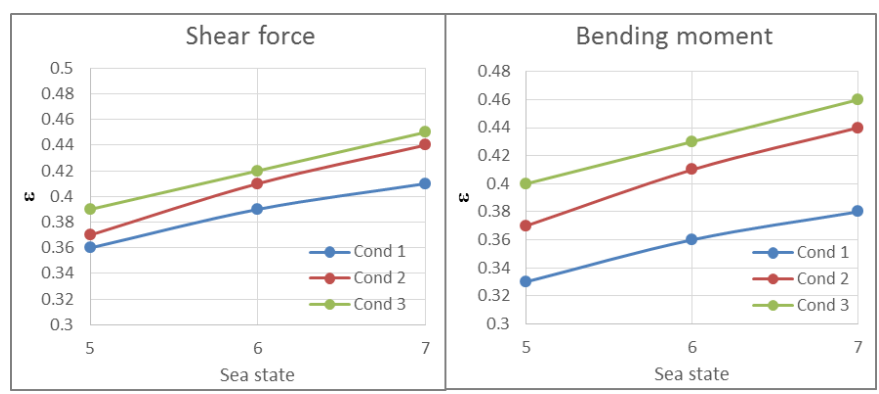

Fig. 5 Bandwidth parameter for SFZ and BMY.

\section{Response estimations for Short term}

Reference [3] summarizes four methods to estimate the response using short term approach, which will be applied to this case. Also classical Rayleigh distribution for peaks will also be applied.

- Distribution of the largest peak in a sequence of $\mathbf{N}$ peaks using order statistics: "Considering a sequence of random variables $Z_{1}, Z_{2}, \ldots, Z_{n}$ representing the peaks of a load ocn a marine structure, and assuming that these peaks are identically distributed and statistically independent, the cumulative distribution function (cdf) of the largest one using order statistics is given by", [3]:

$$
F_{Z_{N}}(z)=P\left[\max \left(z_{1}, z_{2}, \ldots, z_{N}\right) \leq z\right]=\left[F_{Z}(z, \varepsilon)\right]^{N}
$$

Rice's distribution is used as the initial distribution:

$$
\begin{aligned}
F(x, \varepsilon)=\Phi\left(\frac{x}{\varepsilon \sqrt{m_{0}}}\right) & \\
& -\sqrt{1-\varepsilon^{2}} e^{-\frac{1}{2}\left(\frac{x}{\sqrt{m_{0}}}\right)^{2}} \Phi\left(\frac{\sqrt{1-\varepsilon^{2}}}{\varepsilon} \frac{x}{\sqrt{m_{0}}}\right)
\end{aligned}
$$

where: $\Phi(u)=\int_{-\infty}^{u} \frac{1}{\sqrt{2 \pi}} e^{-\frac{1}{2} v^{2}} d v$.
In the equation above, $m_{o}$ is the zero-th order moment of the Spectral density and corresponds to the variance, $T$ and $T_{m}$ are the total duration time and the modal period of the process, and, $\varepsilon$ is the Spectral width parameter.

- Asymptotic type I distribution: this method assumes that as the number of peaks increses to infinite, the cdf of extremes converges to:

$$
F(x)=\exp \left\{-e^{-\alpha_{n}\left(x-u_{n}\right)}\right\}
$$

In the previous equation, parameters $\alpha_{N}$ and $u_{N}$ depend on the initial distribution, which in this case is taken Rice's, described previously:

$$
\alpha_{N}=\frac{N \varepsilon}{\sqrt{2 \pi m_{0}}} e^{-\frac{\alpha^{2}}{2}}+\frac{N \varepsilon \beta}{\sqrt{m_{0}}} e^{-\frac{\alpha^{2}}{2} \varepsilon^{2}} \Phi[\beta]
$$

$$
\begin{gathered}
u_{N}=m_{s} \pm \sqrt{2 m_{0} \ln \left(\frac{\sqrt{1-\varepsilon^{2}} \Phi[\beta]}{1 / N-\Phi[-\alpha]}\right)}, \\
\alpha=\frac{u_{N}-m_{s}}{\varepsilon \sqrt{m_{0}}}, \text { and } \\
\beta=\sqrt{1-\varepsilon^{2}} \alpha
\end{gathered}
$$

It may be notice that $u_{N}$ depends on $\alpha$, and this depends on $u_{N}$, so for the evaluations, a simple iterative process is implemented. Initial value for $u_{N}$ is: $u_{N O}=m_{s}+\sqrt{2 m_{0} \ln (N)}$, where, $m_{s}$ is the mean value of Shear Force or Bending moment, which are taken as those values in calm water, from Fig. 3.

- Extreme value distribution base on upcrossing analysis: rather than using the time history, the distribution of the largest peak may be determined from upcrossing analysis, and if so, it may be shown that the probability that the largest value is less than a certain level $x$ during a period $T$ is given by:

$$
P[\max (X(t) ; 0 \leq t \leq T) \leq x]=e^{-v_{x}^{+} T},
$$

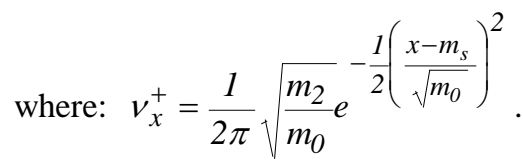

$m_{s}$ has the same meaning than in the previous method. 
- Extreme value distribution based on a two-state description of a random process: as is mentioned in [3], Vanmarcke considered a two-state description of the time history $X(t)$ of the time to first passage across a specified barrier as:

$$
\begin{aligned}
& F(x)= \\
& \exp \left(-\frac{1}{2 \pi} \sqrt{\frac{m_{2}}{m_{0}}} T\left(\frac{1-e^{-\sqrt{2 \pi} q\left(\frac{x-m_{s}}{\sqrt{m_{0}}}\right)}}{1-e^{-\frac{1}{2}\left(\frac{x-m_{s}}{\sqrt{m_{0}}}\right)^{2}}}\right) e^{-\frac{1}{2}\left(\frac{x-m_{s}}{\sqrt{m_{0}}}\right)^{2}}\right)
\end{aligned}
$$

Where $\mathrm{q}$ is a band width parameter defined as:

$$
q=\sqrt{1-\frac{m_{1}^{2}}{m_{0} m_{2}}}, 0 \leq q \leq 1 .
$$

\section{- Rayleigh distribution for peaks:}

Using Rice's formulation, as the initial distribution in the first method, and assuming that the process is narrow banded, Rayleigh distribution is obtained for peaks:

$$
F(x)=1-e^{-\frac{1}{2}\left(\frac{x}{\sqrt{m_{0}}}\right)^{2}}
$$

Applying the five formulations described, Cumulative distribution functions were calculated for Shear Force and Bending Moment, for different sea states, for the three loading conditions. They are shown with Internal force in the abcissas, and cumulative in the ordinates, for sea states 6 and 7 .

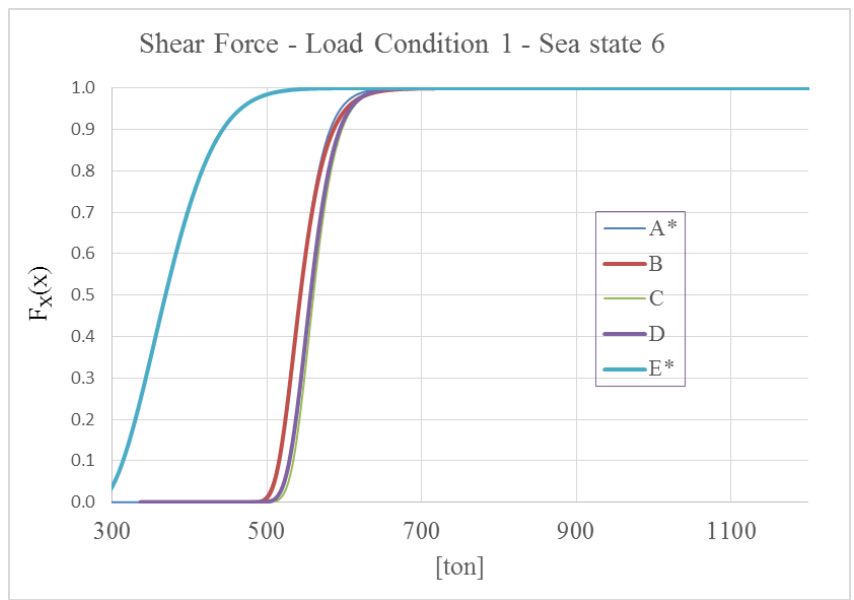

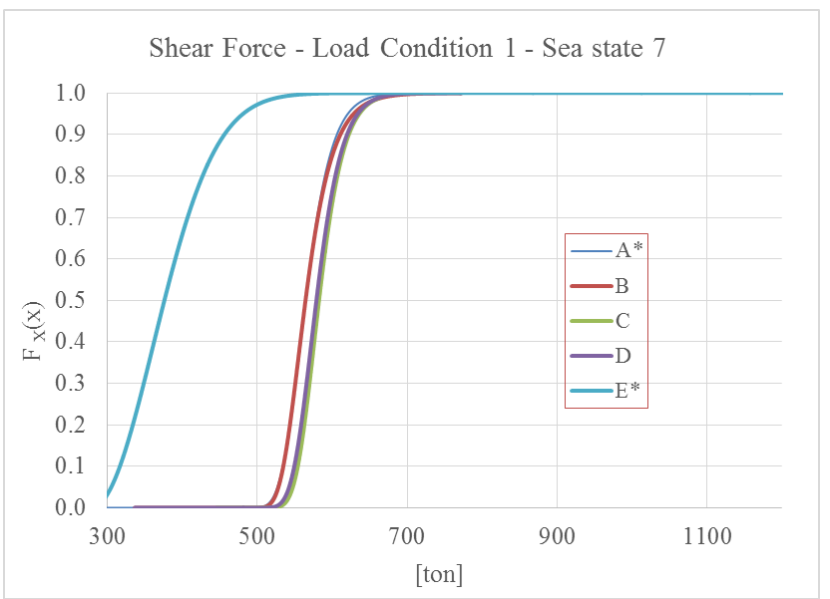
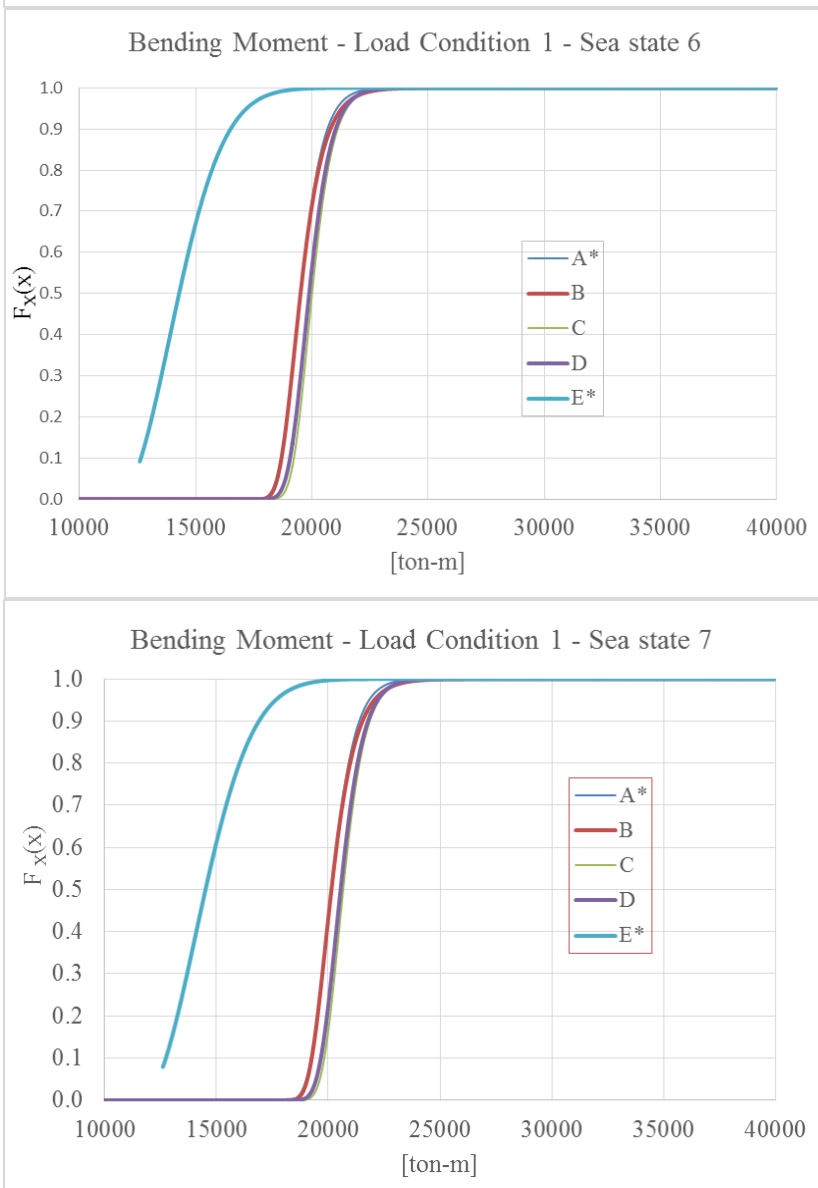

Fig. 6 Cumulative distribution function for SFZ and BMY.

\section{LONG TERM APPROACH}

\section{A. Sea conditions through navegation route}

For the present analysis, it is considered that the ship sails acrross the Atlantic, from northern South America and Europe, has a useful life of 20 years, and operates 2000 hours in a year, [5]. Following it is reproduced a map identifying regions where frequency of sea states information is available.

13 $^{\text {th }}$ LACCEI Annual International Conference: "Engineering Education Facing the Grand Challenges, What Are We Doing?" July 29-31, 2015, Santo Domingo, Dominican Republic 


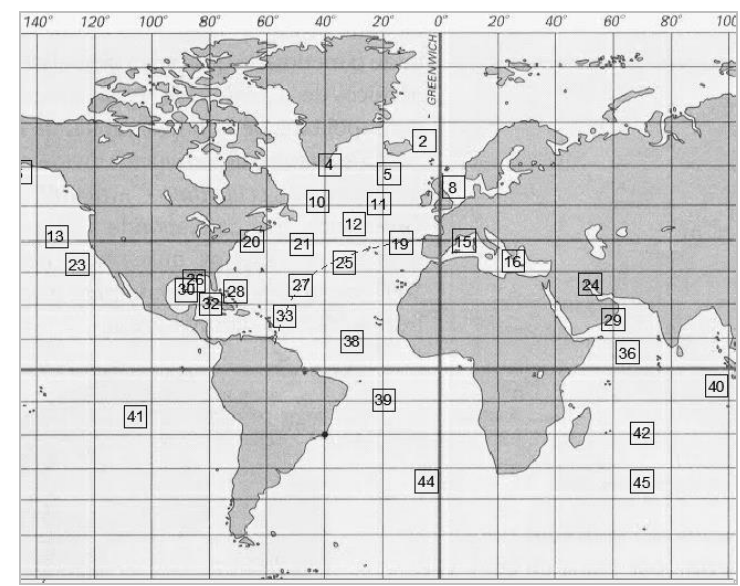

Fig. 7 Geographic regions in the route, [8].

TABLE V

CHARACTERISTICS OF REGIONS IN ROUTE OF THE VESSEL

\begin{tabular}{|c|c|c|c|c|c|c|c|c|}
\hline Region & \multicolumn{2}{|c|}{19} & \multicolumn{2}{|c|}{25} & \multicolumn{2}{|c|}{27} & \multicolumn{2}{|c|}{33} \\
\hline Location & $39 \mathrm{~N}$, & $14 \mathrm{~W}$ & $32 \mathrm{~N}$ & $34 \mathrm{~W}$ & $27 \mathrm{~N}$ & $48 \mathrm{~W}$ & $17 \mathrm{~N}$ & $54 \mathrm{~W}$ \\
\hline $\begin{array}{l}\text { Significant } \\
\text { Height [m] }\end{array}$ & 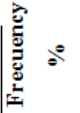 & 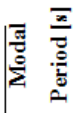 & 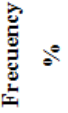 & 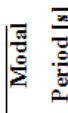 & 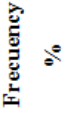 & 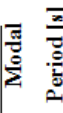 & 氖 & 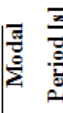 \\
\hline $0-1$ & 2.16 & 6.0 & 41.61 & 6.0 & 41.51 & 6.0 & \begin{tabular}{|l|l|}
11.15 \\
\end{tabular} & 6.0 \\
\hline $1-2$ & \begin{tabular}{|l|l|}
25.45 \\
\end{tabular} & 6.0 & 29.43 & 6.0 & 38.34 & 6.0 & 38.5 & 6.0 \\
\hline $2-3$ & \begin{tabular}{|l|}
19.31 \\
\end{tabular} & 7.5 & 15.2 & 7.5 & 13.55 & 7.5 & 32.83 & 8.0 \\
\hline $3-4$ & \begin{tabular}{|l|l|}
13.44 \\
\end{tabular} & 9.0 & 7.16 & 9.0 & 4.16 & 9.0 & \begin{tabular}{|l|}
12.92 \\
\end{tabular} & 9.5 \\
\hline $4-5$ & 9.24 & 11.0 & 3.8 & 11.0 & 1.52 & 11.0 & 3.68 & 10.5 \\
\hline $5-6$ & 4.92 & 11.5 & 1.64 & 12.0 & 0.66 & 11.5 & 0.66 & 12.5 \\
\hline $6-7$ & 2.70 & 12.5 & 0.75 & 12.5 & 0.21 & 12.5 & 0.21 & 13.5 \\
\hline $7-8$ & 1.34 & 12.5 & 0.32 & 14.0 & 0.05 & 14.0 & 0.05 & 14.0 \\
\hline $8-9$ & 0.64 & 14.0 & 0.09 & 14.0 & 0 & - & 0 & - \\
\hline $9-10$ & 0.44 & 15.5 & 0 & - & 0 & - & 0 & - \\
\hline $10-11$ & 0.23 & 16.0 & 0 & - & 0 & - & 0 & - \\
\hline $11-12$ & 0.11 & 16.0 & 0 & - & 0 & - & 0 & - \\
\hline $12-13$ & 0.02 & 17.0 & 0 & - & 0 & - & 0 & - \\
\hline 13-14 & 0 & - & 0 & - & 0 & - & 0 & - \\
\hline $14-15$ & 0 & - & 0 & - & 0 & 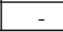 & 0 & - \\
\hline
\end{tabular}

For each sea state, the number of maxima is estimated, with the following results:

TABLE VI

NUMBER OF MAXIMA FOR EACH SEA STATE IN ROUTE OF THE VESSEL

\begin{tabular}{|c|c|c|c|c|c|}
\hline $\begin{array}{c}\text { Sea } \\
\text { state }\end{array}$ & $\begin{array}{c}\text { Significant } \\
\text { height }[\mathbf{m}]\end{array}$ & $\begin{array}{c}\text { Modal } \\
\text { Period [s] }\end{array}$ & $\begin{array}{c}\text { Frequency } \\
\%\end{array}$ & $\begin{array}{c}\text { Time of } \\
\text { occurrence } \\
\text { [days] }\end{array}$ & $\mathbf{N}$ \\
\hline 1 & 0.5 & 6.0 & 29.11 & 489.0 & 7041686 \\
\hline 2 & 1.5 & 6.0 & 32.93 & 553.2 & 7966426 \\
\hline 3 & 2.5 & 7.6 & 20.22 & 339.7 & 3849621 \\
\hline 4 & 3.5 & 9.1 & 9.42 & 158.3 & 1498446 \\
\hline 5 & 4.5 & 10.9 & 4.56 & 76.6 & 608637 \\
\hline 6 & 5.5 & 11.9 & 1.97 & 33.1 & 240800 \\
\hline 7 & 6.5 & 12.8 & 0.97 & 16.3 & 110145 \\
\hline 8 & 7.5 & 13.6 & 0.44 & 7.4 & 46875 \\
\hline 9 & 8.5 & 14.0 & 0.18 & 3.1 & 18922 \\
\hline 10 & 9.5 & 15.5 & 0.11 & 1.8 & 10301 \\
\hline 11 & 10.5 & 16.0 & 0.06 & 1.0 & 5216 \\
\hline 12 & 11.5 & 16.0 & 0.03 & 0.5 & 2495 \\
\hline 13 & 12.5 & 17.0 & 0.01 & 0.1 & 427 \\
\hline
\end{tabular}

Summing the number of peaks for each sea state, last column, a total value of $2.14 \mathrm{E} 7$ is obtained.

According to [1], [3] and [9], Weibull function describes adequately Ship hull bending moment probability distribution for long period of times. In this work, that distribution function is also applied to Shear force. Considering Total Bending moment and Shear force as random variables, (summing waves and still water), Weibull pdf and cdf are:

$$
\begin{gathered}
f(x)=\frac{l}{k}\left(\frac{x}{k}\right)^{l-1} e^{-(x / k)^{l}} \\
F(x)=1-e^{-\left(\frac{x-m_{s}}{k}\right)^{l}}
\end{gathered}
$$

where $l$ and $k$ are Weibull parameters, and $m_{s}$ is the value of Shear force or Bending moment in still water. Notice that if $l=2.0$ Rayleigh distribution is recovered. In the present case, those two parameters are estimated assuming an extreme weather condition, following the process:

i.- A range for $l$ is assumed between 0.5 and 2.0, [9].

ii.- Value of $k$ es calculated using the following:

$$
\begin{gathered}
\mu_{x}=k \Gamma(1+1 / l) \\
\sigma_{x}^{2}=k^{2}\left\lfloor\Gamma(1+2 / l)-\Gamma^{2}(1+1 / l)\right\rfloor
\end{gathered}
$$

where $\mu_{x}$ and $\sigma_{x}$ are the mean and standard deviation of the process, and $\Gamma(t)$ is Gamma function, defined as:

$$
\Gamma(t)=\int_{0}^{\infty} y^{t-1} e^{-y} d y
$$

Also from Statistics. [10]:

$$
\overline{x^{2}}=(\bar{x})^{2}+\sigma^{2}, \text { or, } R M S^{2}=\mu_{x}^{2}+\sigma_{x}^{2}
$$

Combining these these equation, value for $k$ may be found.

iii.- A value of probability of exceedence is taken, which is related to the Total number of ocurrences or peaks, previously estimated:

$$
P_{e T(R E F)}=\frac{1}{N_{T}}=\frac{1}{21399996}=4.67 \mathrm{E}-8
$$


iv.- Using Shear force and Bending moments are calculated for the above value of probability of exceedence:

$$
P_{e T}=\sum_{i=1}^{13} P_{e(i)} f(i)
$$

where $P_{e(i)}$ is the probability of excedeence of each sea state, $f(i)$ is the percentage of that sea state in the ship's route.

v.- Results for the more demanding loading condition (1: ballast) and are compared with a critical value for both internal forces. In this work, critical values are considered as those obtained in short term with an extreme sea state, significant wave height and modal period of $22.7 \mathrm{~m}$ and 24.1 seconds, respectively. Two values of probability of excedeence are applied 1.0E-8 and 1.0E-9, range that include the value estimated previously in step iii, [4].

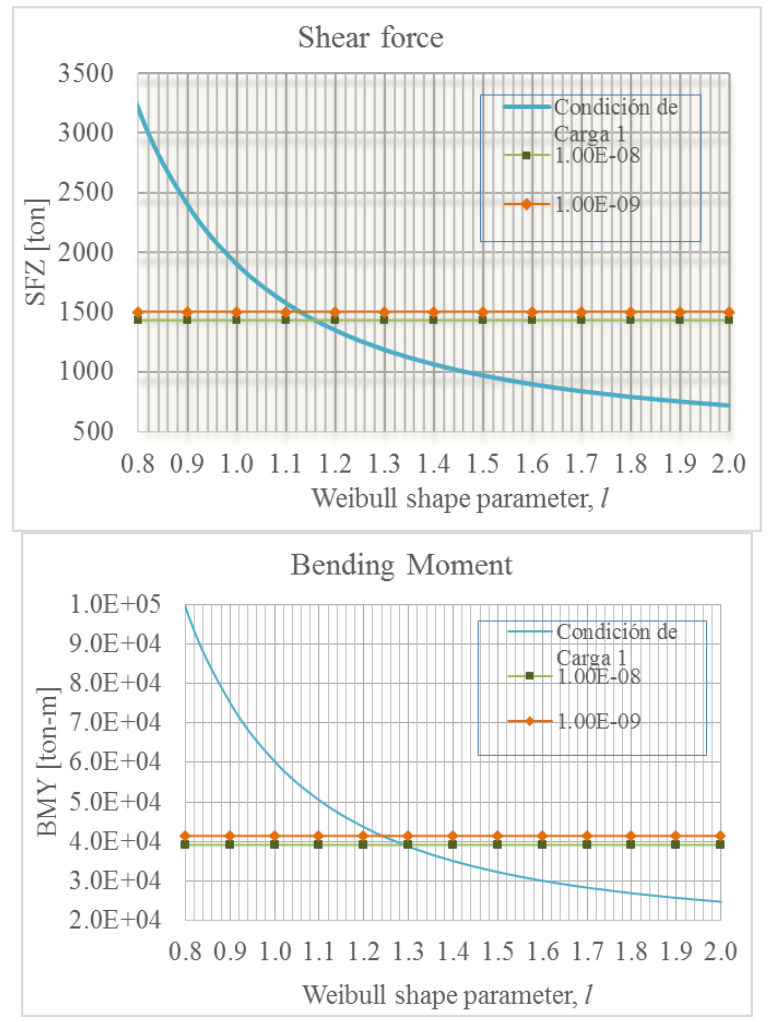

Fig. 8 Weibull parameter for Shear force and Bending moment.

As may be seen from both figures, Weibull shape parameter ranges between 1.14 and 1.16 for $S F Z$, and between 1.25 and 1.30 for $B M Y$.
TABLE VII

SHEAR ForCE AND BENDING MOMENT DESIGN VAUES. [4]

\begin{tabular}{|c|c|c|c|}
\cline { 2 - 4 } \multicolumn{1}{c|}{} & \multicolumn{3}{c|}{ Shear Force [ton] } \\
\hline $\boldsymbol{l}$ & Cond. 1 & Cond. 2 & Cond. 3 \\
\hline 1.14 & 1476 & 1321 & 1288 \\
\hline 1.16 & 1431 & 1276 & 1243 \\
\hline & \multicolumn{3}{|c|}{ Bending moment [ton-m] } \\
\hline 1.25 & 40974 & 35959 & 35417 \\
\hline 1.30 & 38710 & 33663 & 33013 \\
\hline
\end{tabular}

\section{COMPARISON OF DIFFERENT APPROACHES}

\section{A. Cuasistatic calculations}

Classical naval engineering method poses the ship in two extreme situations, with crest at midships, Hogging, and, at ehe ends, Sagging, and establishing a cuasiestatic equilibrium; wave length equals ship length. Then analyzing different sections along the length, internal force and moment may be estimated. For the wave height, reference [1], specifies a value of $1.1 \sqrt{L[\text { feet }]}$, that produces a value of 6.4 meter, using $112 \mathrm{~m}$ of length.

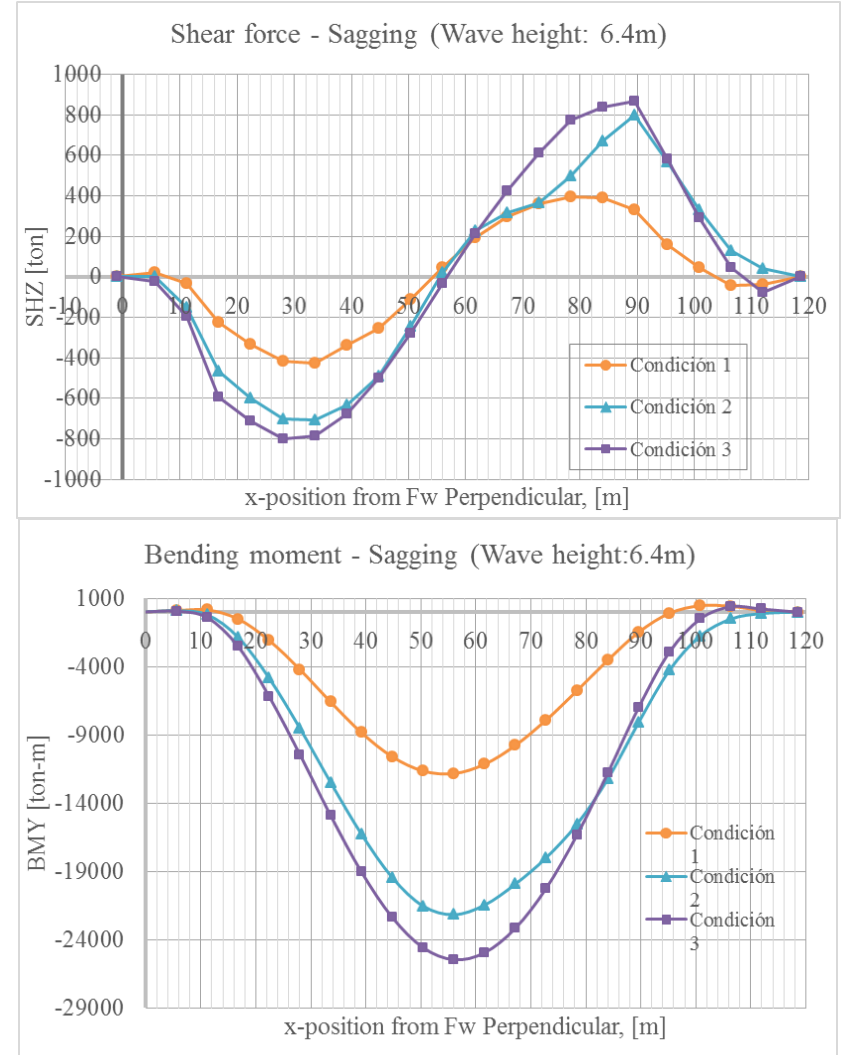

Fig. 9 Cuasistatic Shear force and Bending moment in Sagging.

$13^{\text {th }}$ LACCEI Annual International Conference: "Engineering Education Facing the Grand Challenges, What Are We Doing?" July 29-31, 2015, Santo Domingo, Dominican Republic 


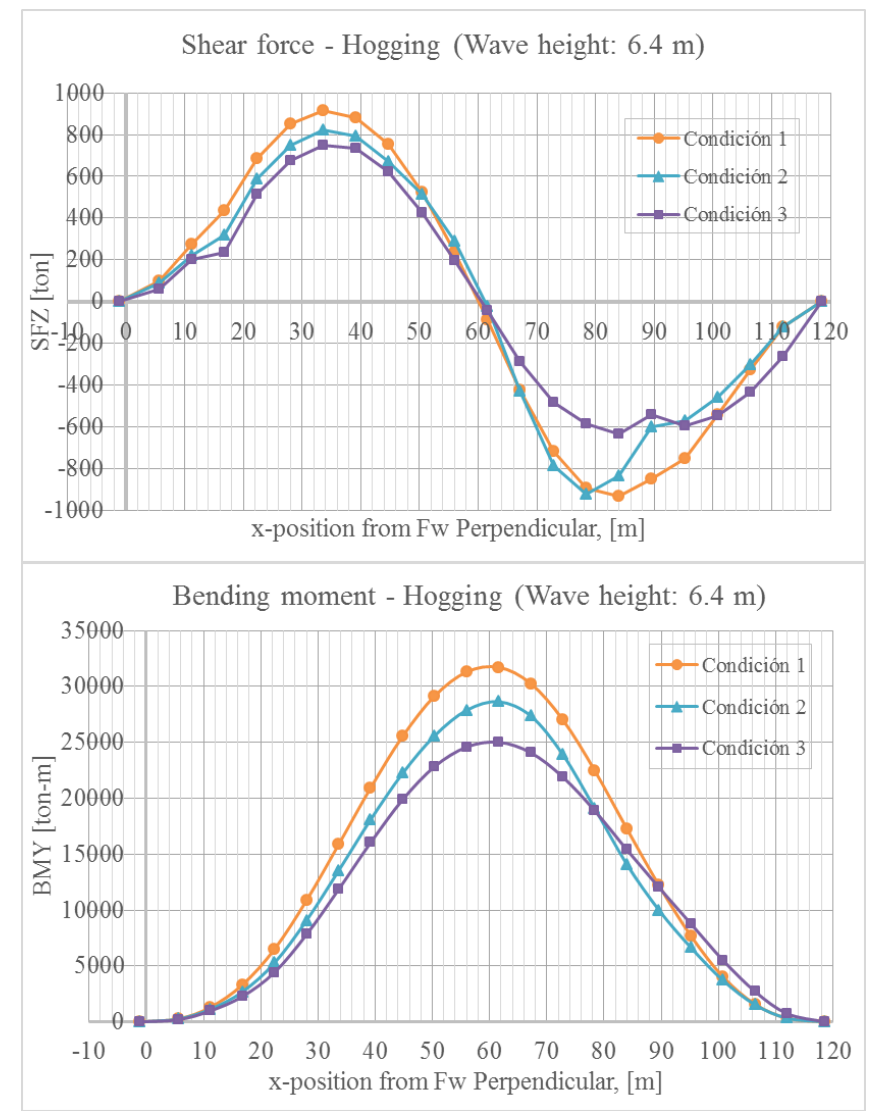

Fig. 10 Cuasistatic Shear force and Bending moment in Hogging.

\section{B. Formulations from a Ship Classification Society}

According to Longitudinal Strength section of Det Norske Veritas rules, Midships still water Bending moment is not smaller than, [2]:

$$
\begin{aligned}
& M_{\text {sHogging }}=.0 .065 C_{w} L^{2} B\left(C_{B}+0.7\right),[\mathrm{kN} \mathrm{m}], \\
& M_{\text {sSagging }}=C_{w} L^{2} B\left(0.1225-0.015 C_{B}\right),[\mathrm{kNm}],
\end{aligned}
$$

where $L$ is summer load line length $(114.6 \mathrm{~m}), B$ is moulded breadth (17.2), $C_{B}$ is block coefficient (0.772), and $C_{w}$ is wave coefficient (8.14), according to the length of the ship.

Also, still water shear force is not less than:

$$
Q_{s}=5 k_{s q} \frac{M_{s}}{L},[k N]
$$

where $k_{s q}$ is a factor that varies longitudinally, and $M_{s}$ is the bending moment. At $L / 4$ and $3 L / 4, k_{s q}$ takes highest values equal to 1.0 .

In waves, the mentioned reference, presents the following equations to estimate Bending moment and Shear force, in Hogging and Sagging situations:

$$
\begin{gathered}
M_{w}(\text { Sagging })=-0.11 k_{w m} \alpha C_{w} L^{2} B\left(C_{B}+0.7\right),[\mathrm{kNm}] \\
M_{w}(\text { Hogging })=0.19 k_{w m} \alpha C_{w} L^{2} B C_{B},[\mathrm{kNm}]
\end{gathered}
$$

For ocean operation, $\alpha$ takes a value of 1.0, and, $k_{w m}$ for midship area, is also 1.0.

For Shear force, the following equations apply:

$$
\begin{gathered}
Q_{w P}=0.3 k_{w q p} C_{w} L B\left(C_{B}+0.7\right),[k N], \\
Q_{w N}=-0.3 \beta k_{w q n} C_{w} L B\left(C_{B}+0.7\right),[k N] .
\end{gathered}
$$

Subindex $P$ implies applicable when still water shear force is positive, and, $N$ for negative. For ocean service, $\beta$ values $1.0, k_{w q p}$ values 1.0 for $3 / 4 L$, and, $k_{w q n}$ is 1.73 for $L / 4$ position.

\section{Summary and comparison}

In the following tables, ship hull Total (still water plus wave) force and moment from the four processes are presented:

TABLE VIII

ShEAR FORCE AND BENDING MOMENT DESIGN VALUES, [4].

\begin{tabular}{|c|c|c|c|c|}
\cline { 2 - 4 } \multicolumn{1}{c|}{} & \multicolumn{3}{c|}{ Total Shear Force [ton] } \\
\cline { 2 - 4 } & $\begin{array}{c}\text { Short term } \\
\text { approach }\end{array}$ & $\begin{array}{c}\text { Long term } \\
\text { approach }\end{array}$ & $\begin{array}{c}\text { Cuasistatic } \\
\text { procedure }\end{array}$ & $\begin{array}{c}\text { Formula } \\
\text { Classif. } \\
\text { Society }\end{array}$ \\
\hline Condition 1 & 1133 & 1476 & 884 & \multirow{2}{*}{1573} \\
\hline Condition 2 & 977 & 1321 & 785 & \\
\hline Condition 3 & 1111 & 1288 & 712 & \\
\hline
\end{tabular}

\begin{tabular}{|c|c|c|c|c|}
\cline { 2 - 4 } \multicolumn{1}{c|}{} & \multicolumn{3}{c|}{ Total Bending Moment [ton-m] } \\
\cline { 2 - 4 } & $\begin{array}{c}\text { Short term } \\
\text { approach }\end{array}$ & $\begin{array}{c}\text { Long term } \\
\text { approach }\end{array}$ & $\begin{array}{c}\text { Cuasistatic } \\
\text { procedure }\end{array}$ & $\begin{array}{c}\text { Formula } \\
\text { Classif. } \\
\text { Society }\end{array}$ \\
\hline Condition 1 & 34243 & 40974 & 31507 & \multirow{2}{*}{44944} \\
\hline Condition 2 & 26607 & 35959 & 28253 & \\
\hline Condition 3 & 30425 & 35417 & 24800 & \multirow{2}{*}{} \\
\hline
\end{tabular}

Regulations from ship classification societies try to cover as many situations as they can, and of course this implies the inclusion of safety factors. As a result, Shear force and

13 $^{\text {th }}$ LACCEI Annual International Conference: "Engineering Education Facing the Grand Challenges, What Are We Doing?" 
Bending moment design values from those formulations are higher than those obtained from Short and Term apporaches. For this vesses, values from ship classification society rules are about $10 \%$ higher than those from Long term approach.

\section{CONCLUSIONS AND RECOMMENDATIONS}

In this work Shear Force and Bending Moment in a 7440 DWT tanker hull structure were calculated applying Short and Long term approaches, Cuasistatic procedure and formulations from a ship classification society. For the first two calculations, linear response to regular waves was estimated using a computer program which applies Strip theory. For the long term, a ship route which crosses Atlantic ocean is considered, where information on sea state frequncy was available. After this process it can be concluded:

1. Maximum values of Shear Vertical force responding to regular waves appear at about $L / 4$ from Forward Perpendicular, for all three loading conditions analyzed; in the case of Bending moment, maximum values appear at midships. As was expected all these maxima appear when the ship sails in waves coming from the bow, when ship response in the vertical plane, Heave and Pitch are maximum.

2. Wave length which produce maximum internal force and moment is about $90 \%$ of Length between perpendiculars. Wave crests act as supports of the hull beam, and in the two extreme situations, crest on Midships or at the ends, structural demand is high. When wave length decreases, separation between "supports" reduces, and internal forces also decrease. When wave length increases, ships tend to raise with the surface, reducing its dynamic effect.

3. In the Short term approach to estimate internal loads, as the considered sea state increases, significant wave height is larger and the structural demand also increases. Keeping the assumption of linearity is commonly acceptd for the vertical plane of a ship, but probably this cannot be defended when the response is very high. So the results obtained for higher sea states have to accepted with caution.

From the results of Short term approach, using different methods of calculation, basically the first four produce results very similar. The last one, classical Rayleigh for distribution of maxima provides results quite different from the others. The big simplification of this formulation is to assume that the random phenomena is narrow banded. So even though the parameter $\varepsilon$ is small enough, for the present case this simplification must not be accepted to estimate Shear force and Bending moment to design a ship hull structure.
4. From the Long term approach calculations, the parameters for the Weibull function lie in the range of expected values. For its determination, even though the band width parameter is lower than 0.6 , they cannot be considered as narrow banded, since this would result in a Rayleigh distribution, which with our Short term approach results proved to be invalid. As for the results, Internal force and moment are maxima for the lower displacement condition.

5. Finally, comparing results from the four employed formulations, and as it was expected, the results from ship classification society rules produce values about $10 \%$ higher than those from Long term method. Short term approach results are lower than the Long approach, and coincides in pointing at the lower displacement condition as the one that demands the most from the hull structure. Cuasiestatic estimation depends strongly on the equivalent wave height, which for a small ship requires different formulations than that for a larger one.

Recommendations for future work.- Since a Long approach provides information during the whole life of a ship, next step would be to develop a fatigue analysis of some structure details; this will allow to consider another failure mode of the structure. In this work, the response of the hull structure was estimated under an assumption of linearity; this simplification should be investigated for the higher sea states. It is common to observe ships with ages above 20 years operating in our waters, and of course the structural demand that they find in this world region are lower than those in the Atlantic ocean; still, it would be useful to compare the response in our waves, but for that. information on frequency of sea states by zone is required, and hopefully in the future those number will be available.

\section{REFERENCES}

[1] A. Mansour, \& D. Liu, Strength of Ships and Ocean Structures, NY: SNAME, 2008.

[2] Det Norske Veritas, Rules for Classification, "Hull Structural Design Ships with Length 100 Metres and Above", DNV, 2008.

[3] A. E. Mansour, An Introduction to Structural Reliability Theory, SSC Ship Structure Committee \#351, 1990.

[4] L. Salazar, Estimation of Dynamical Shear Force and Bending Moment in a 7440 DWT tanker subject to Extreme Irregular Sea. Naval Engineer Undergraduate thesis, FIMCBOR-ESPOL, Guayaquil, 2014

[5] C. E. Egas, Personal Comunication. Guayaquil, 2013.

[6] A. I. Raff, Program SCORES. Ship structural response in waves, Ship Structure Committee \#230, 1972.

[7] R. Bhattacharyya, Dynamics of Marine Vehicles, NY: John Wiley \& Sons, Inc., 1978.

[8] W. T. Lee, Global Wave Statistics for Structural Design Assessments. Naval Surface Warfare Center. NSWCCD-HD-1048-01, 1995.

[9] W. Munse, Fatigue Criteria for Ship Structure Details. University of Illinois, 1981.

[10] G. M. Zurita, Probability and Statistics (in Spanish), Guayaquil: ESPOL, 2008. 


\section{APPENDIX}

RMS AND BANDWIDTH FOR SHEAR FORCE AND BENDING MOMENT
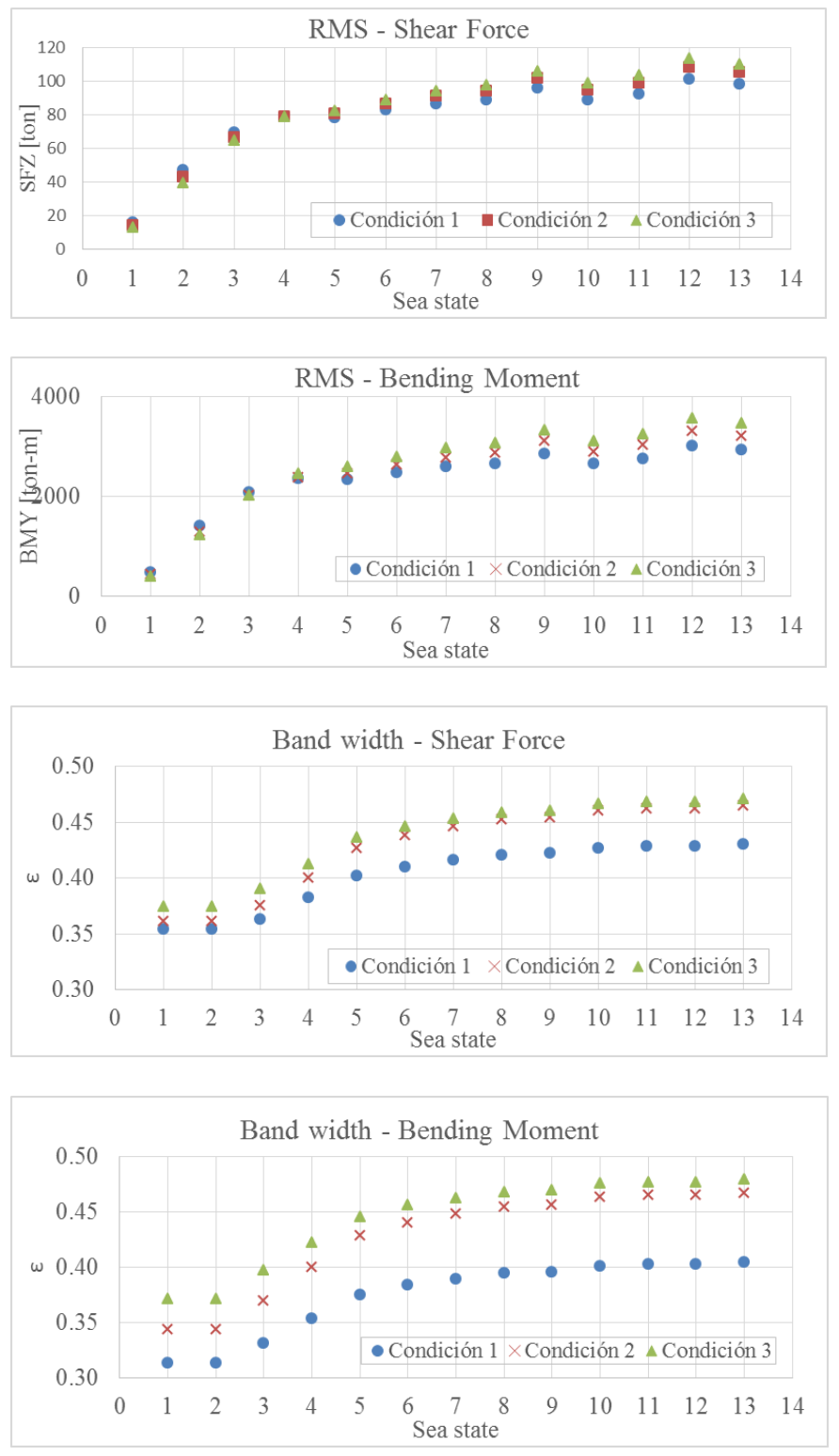

$1^{\text {th }}$ LACCEI Annual International Conference: "Engineering Education Facing the Grand Challenges, What Are We Doing?" July 29-31, 2015, Santo Domingo, Dominican Republic 